\title{
Births, economic growth, mortality and murder in a developing country
}

\author{
Paul A. Bourne \\ Socio-Medical Research Institute, Kingston, Jamaica (Formerly, Department of Community Health and Psychiatry, The University \\ of the West Indies, Mona, Jamaica); paulbourne1@yahoo.com
}

Received 29 July 2011; revised 20 September 2011; accepted 10 October 2011

\begin{abstract}
Background: In 1960, total fertility rate in Jamaica was 5.6 children per woman which declined by $57.5 \%$ in 2008 . The reduction in fertility is primarily attributable to contraceptive measures; but murder and other selected macroeconomic variables have never been included in the literature. Objectives: This study examines murder, mortality, and selected macroeconomic variables are factors of births, using data for Jamaica from 1989-2009. Methods: The study is a secondary data analysis of statistics on Jamaica from 19892009 but also includes data on births from 1900s. Findings: In the decade of the 1950s, births increased by $79.9 \%$ over the decade of $1900 \mathrm{~s}$, grew by $22.4 \%$ in the 1960 s over the previous decade and declined by $17.6 \%$ in 2000 s compared with the 1990s. Four emerged as statistically significant predictors of Inbirth-inflation, GDP per capita growth, mortality and murder, with an explanatory power of $90.6 \%-F=19.291, P<0.0001$. With there being a strong statistical correlation between annual exchange rate and murder $\left(r_{s}=\right.$ 0.962 ), when murder was excluded and replaced by annual exchange rate, the factors influencing Inbirth was exchange rate, inflation, unemployment, GDP per capita growth and mortality-all factors account for $92.2 \%$ of the variability in Inbirth-F $=30.572, P<0.0001$. Conclusion: Murder is more that a crime it is a cause of birth decline, suggesting that public health practitioners as well as epidemiologists must take this factor into account as it is a birth determinant.
\end{abstract}

Keywords: Births; Fertility; Fertility Rates; Murder; Mortality; Poverty; GDP Growth; Inflation; Exchange Rate; Jamaica

\section{INTRODUCTION}

The study of birth has a long history in demography
[1-4], which dates back to its beginning in the late seventeenth century [5]. In demography, investigations are usually carried out on fertility which relates to the number of live births a woman actually had, fecundity that denotes the physiological capacity of the woman to bear children and other issues of births such as crude birth, age-specific fertility, and general fertility as well as parity progression ratios. Empirical evidence showed that total fertility rate in the 1960s was 5.6 per woman in Jamaica and this has dramatically declined to 2.4 per women in 2008; in 2009, 69 out of every 100 births occurred to women less than 30 years and the crude birth rate in 2010 was 15.96 compared to 16.69 in 2010 [6,7]. The reduction in fertility per woman has been attributable to family planning measures which were introduced in the 1970s [8]. Like in Jamaica, family planning measures in China, Africa and other developing nations are responsible for the reduction in population growth rate [9-13]. Ascribing family planning measures to the decline in fertility is accepting that there are determinants of births (or factors affecting fertility).

Kiser and Whelpton [14] classified factors of fertility in social and psychological variables in a study which dates back to the 1950s. Other scholars have expanded on the categorization of factors identified by Kiser and Whelpton [4,15-17]. It follows that the decline in fertility cannot be limited to family planning measures as the factors of fertility encompasses crowding, age of first sexual intercourse, age of marriage, personal attitude towards family, income, fecundity, personal aspirations, and other non-contraceptive variables. In the United States and England fertility began declining before the beginning of the nineteenth century [4], and this was attributable to contraceptives which were freely available in 1820 . Then in the 1920s-1930s, there was the great economic depression that saw the fall in marriage rates and according to Cox "....births were relatively few" [4], suggesting a correlation between fertility and economic growth (or the lack of).

Using a nationally probability sample of 1338 respondents, Powell et al. [18] found that crime and violence were the leading concern of most Jamaicans. Another aca- 
demic researcher noted that, in respect to murders, Jamaica was ranked number 1 in the Caribbean [19]; and in 2005, it was the highest in the world [20]. From a probability sample of 1595 Jamaicans, the LAPOP 2006 survey revealed that 1 in every 10 respondents was victimized of crime [20], indicating that crime, violence and victimization are rampant in the society and account for a percentage of premature mortality. Despite the aforementioned fact, studies on crimes (including murders) have been primarily from criminological or sociological perspectives [21-25]. Crimes and violence are not seen as a cause of mortality, which accounts for their non-usage in health inquiry. However, McDonald [26] posited that violence is a public health issue. This suggests that murders may have some explanation for birth changes, even though this has never been investigated in literature, particularly in Caribbean.

Recognizing the paucity of information in the literature on a single inquiry that evaluates birth, mortality and murder as well as other macroeconomic variables (like poverty, unemployment, inflation, exchange rate, Gross Domestic Product (GDP) per capita), this study examines murder, mortality, and selected macroeconomic variables are factors of births, using data for Jamaica from 1989-2009.

\section{THEORETICAL FRAMEWORK}

Bongaarts [15] developed a mathematical model which proximate the determinants of fertility. He forwarded that total fertility rate (TFR) can be expressed as:

$$
\mathrm{TFR}=\mathrm{C}_{\mathrm{m}} \times \mathrm{C}_{\mathrm{c}} \times \mathrm{C}_{\mathrm{a}} \times \mathrm{C}_{\mathrm{i}} \times \mathrm{TNM}
$$

where $C_{m}$ denotes the age-specific proportion married; $C_{c}$ means proportion of non-contraception; $\mathrm{C}_{\mathrm{a}}$ represents the total induced abortion (which is the number of abortion among women ages 15 - 44 years by 30 ); $C_{i}$ connotes the average duration of lactational infecundability, and TNM is total natural marital fertility rate.

Using calculus by finding the logarithm of both sides give:

$\operatorname{lnFertility~}=\ln \mathrm{C}_{\mathrm{m}}+\ln \mathrm{C}_{\mathrm{c}}+\ln \mathrm{C}_{\mathrm{a}}+\ln \mathrm{C}_{\mathrm{i}}+\ln \mathrm{TNM}(2)$

The general principle embedded in the Bongaarts' model is applied to this work. Bongaarts' framework highlights that the relationship between fertility (or birth) and identified independent variables $\left(\mathrm{C}_{\mathrm{m}}, \mathrm{C}_{\mathrm{c}}, \mathrm{C}_{\mathrm{a}}, \mathrm{C}_{\mathrm{i}}, \mathrm{TNM}\right)$ is nonlinear that is the general framework used in interpreting factors of birth for this work.

Bongaarts' model may have been influenced by the work of multiplicative framework of Grabill, Kiser and Whelpton's on the decomposition of the number of births in year [27]. Grabill, Kiser and Whelpton's forwarded that number of births in a year $\mathrm{T}$ is given by:

$$
\mathrm{B}(\mathrm{T})=\mathrm{W}(\mathrm{T}) \cdot \frac{\mathrm{M}(\mathrm{T})}{\mathrm{W}(\mathrm{T})} \cdot \frac{\mathrm{O}(\mathrm{T})}{\mathrm{M}(\mathrm{T})} \cdot \frac{\mathrm{B}(\mathrm{T})}{\mathrm{O}(\mathrm{T})}
$$

where $B(T)$ is the number of births in year $t$; $W(T)$ is the number of women aged 15 - 49 years inure $t$; $M(T)$ is the number of married women aged 15 to 49 years in year $\mathrm{T}$, and $\mathrm{O}(\mathrm{T})$ denotes the number of mothers (women of parity one or more) aged 15 to 49 years in years. This formula means that the number of women aged 15 to 49 years alive in year $\mathrm{T}$ by married women aged 15 to 49 years and by mothers aged 15 to 49 years.

By finding the logarithm of both sides of Grabill and colleagues' model gives:

$$
\ln B(T)=\ln W(T) \cdot \ln \frac{M(T)}{W(T)} \cdot \ln \frac{O(T)}{M(T)} \cdot \ln \frac{B(T)}{O(T)}
$$

From the principles within calculus, it follows that the birth is non-linear functions, which was also captured in Bongaarts' model on fertility.

Unlike principles embedded in Bongaarts' [15] as well as Gabill and colleagues' models [27], this work recognizes that birth is a non-linear function and that no parameters were computed for each variable because of the linear nature of variables embedded in the other models. From the principles in calculus, although the variables are non-linear, by finding the logarithm of each side of either Bongaarts' or Grabill and colleagues' model, if parameters were present they would be linear integers while the variables are not. The non-linearity of the variables as well as the linearity of each parameter of the variables were taken into consideration in this work, which is a modification from Grabill and colleagues' model that decomposed birth. These are captured in Equations. [5] and [8], while using different types of variables, as follows:

The birth function (B) is equal to mortality (M), murder (R), GDP per capita growth (GDP), and inflation (I), and can be written as:

$$
\mathrm{B}=\alpha \mathrm{M}^{\beta} \mathrm{R}^{\gamma} \mathrm{GDP}^{\omega} \mathrm{I}^{v}
$$

However, taking the logarithms yields

$$
\ln (\mathrm{B})=\delta+\beta \ln (\mathrm{M})+\gamma \ln (\mathrm{R})+\omega \ln (\mathrm{GDP})+v \ln (\mathrm{I})+\mathrm{e}
$$

where $\delta=\ln (\alpha)$. This is a nonlinear function in the variables $\mathrm{M}, \mathrm{R}, \mathrm{GDP}$ and I, but the parameters are linear, $\delta, \beta$, $\gamma, \omega$, and $v$.

Eq.3 was modified to replace lnExchange rate with lnmurder, making the function to be written as:

$$
\mathrm{B}=\alpha \mathrm{M}^{\beta} \mathrm{U}^{\gamma} \mathrm{GDP}^{\omega} \mathrm{I}^{v} \mathrm{E}^{\rho}
$$

However, taking the logarithms yields

$$
\begin{aligned}
\ln (\mathrm{B})= & \delta+\beta \ln (\mathrm{M})+\gamma \ln (\mathrm{U})+\omega \ln (\mathrm{GDP})+v \ln (\mathrm{I}) \\
& +\rho \ln (\mathrm{E})+\mathrm{e}
\end{aligned}
$$

with the exclusion of annual exchange rate (exchange, E), unemployment emerged as a factor (U). The building of these models were developed in the hypotheses, expounded upon and tested therein. 


\subsection{Data and Methods}

The current work is a secondary data analysis. Data sources were from Jamaica Survey of Living Conditions (JSLC) [28] on illness rate and poverty; Economic and Social Survey of Jamaica on poverty [29]; Statistical Digest on inflation and annual exchange rate [30], Demographic Statistics on mortality, crude death rate [6], and the Statistical Department of the Jamaica Constabulary Force on murders [31]. The period for this work is primarily from 1989 to 2009; but also includes data on births from 1900 [7].

The JSLC is jointly conducted by the Planning Institute of Jamaica (PIOJ) and the Statistical Institute of Jamaica (STATIN) [28]. The JSLC is a nationally representative cross-sectional descriptive survey which uses stratified random sampling and comprised data on households' characteristics, health, education, expenditure, social programmes, and other information. An administered questionnaire modeled from the World Bank's Living Standards Measurement Study (LSMS) household survey [32] is used to collect the data. There are some modifications to the LSMS, as JSLC is more focused on policy impacts.

The JSLC used a two-stage stratified random sampling design where there was a Primary Sampling Unit (PSU) and a selection of dwellings from the primary units. The PSU is an Enumeration District (ED) which constituted of a minimum of 100 dwellings in rural areas and 150 in urban areas. An ED is an independent geographic unit that shares a common boundary. This means that the country was grouped into strata of equal size based on dwellings (EDs). Based on the JSLC, the PSUs is a listing of all the dwellings and this was used as the sampling frame from which a Master Sample of dwelling was compiled [28]. According to the JSLC [19], the sample was weighted to reflect the population of the nation. The households in the JSLC were interviewed during three to four years, after which a new representative sample was drawn. In this study, we used aggregate to the parish level, which means that analysis can be made across periods (or over time).

The Economic and Social Survey of Jamaica (ESSJ) is a publication of the PIOJ which collates information on social and economic indicators of Jamaica. We collected data mainly on unemployment rate in Jamaica from 1989 to 2009 [29].

The annual exchange rate of the Jamaican to the United States' dollar were collected from the Bank of Jamaica's (BoJ) publication [30] and the Gross Domestic Product (GDP) information was had from the International Monetary Fund's World Economic Outlook [32]. Data on murder were obtained from Statistical Unit, Jamaica Constabulary Force (JCF) for the periods, 1989-2009.

\subsection{Statistical Analyses}

Data were entered and stored into Microsoft Excel and
SPSS for Window version 17.0 (SPSS Inc; Chicago, IL, USA) which were both used to analyze the data. Pearson's product Moment Correlation was used to assess the bivariate correlation between particular macroeconomic and other variables. Scatter diagrams and best fit models were used on the data. Ordinary least square (OLS) regression analyses were used to establish the model for 1) log birth. Ordinary least square regressions were utilized to analyze the possible explanatory variables. A p-value of $5 \%$ or lower was chosen to indicate statistical significance. The variables that were entered into the model were significant in the bivariate correlation (Pearson's Product Moment Correlation). In any instance where collinearity existed $(r>0.7)$; the variables were entered independently into the model to determine as to which of those should be retained during the final model construction. The final decision on whether or not to retain the variables was based on the variables' contribution to the predictive power of the model and its goodness of fit. Each scatter plot was modeled by a linear, power, exponential or polynomial best fit function based on the data, with the aid of Excel.

Using the principle of parsimony (all the variables that should be included are entered and not omitted from the model), which was tested by the huge differences in adjusted $\mathrm{R}^{2}$ from the $\mathrm{R}^{2}$. Hence, the model for birth function must see the least differences between the two aforementioned issues.

Illness rate is a percentage of people in the population who reported having an illness in the survey week. Illness is an indicator of poor ("bad") health as only since 2007 the JSLC began collecting data on self-rated health status. Prior to that year, data on illness was collected, which was used to plan for the health of the populace.

\subsection{Variables}

The exchange rate (or Jamaican exchange rate) is the number of Jamaican dollars needed to purchase one United States’ dollar (US\$1).

Murder denotes the number of people unlawfully killed (a crime causing death without a lawful excuse) within a particular geopolitical zone (excluding police killings or homicides).

Birth (or live birth) according to the Statistical Institute of Jamaica [6] is the "result of the complete expulsion or extraction from its mother of a product of conception, irrespective of the duration of pregnancy, which after such separation, breathes or shows any other evidence of life such as beating of the heart, pulsation of the umbilical cord, or definite movement of voluntary muscles, whether or not the umbilical cord has been cut or the placenta is attached; each product or such a birth is considered live-birth".

Examining the quality of data on live births in Jamaica, McCaw-Binns and colleagues found that 94 out of every 
100 live births were registered by one year of age [32]. A later study conducted by Fox et al. [33] found that 89.9\% of the reported births by the Registrar General's Department were covered, and the Statistical Institution of Jamaica estimated that this was 93\% [6]. Based on a study done by Mathers [34] established that in excess of $90 \%$ of complete coverage of data denotes high quality data, suggesting that live births in Jamaica is of high quality.

Hypothesis. This paper will test the following hypotheses ((1)-(7))

lnbirth $=\mathrm{f}(\operatorname{lnMurder}$ GDP per capita growth $)+\mathrm{e}$

lnbirth $=\mathrm{f}$ ( lnPoverty, lnUnemployment,

$$
\text { lnillness, lnMortality) }+\mathrm{e}
$$

lnbirth $=\mathrm{f}$ (lnPoverty, Exchange Rate, InInflation,

$$
\text { lnUnemployment, mortality, InMurder) + e }
$$

lnbirth $=\mathrm{f}$ (Exchange Rate, lnInflation,

$$
\begin{aligned}
& \text { InUnemployment, GDP per capita } \\
& \text { growth, Inmortality)+e }
\end{aligned}
$$

lnbirth $=\mathrm{f}(\ln$ Inflation, lnUnemployment, GDP per capita growth, Inmortality, lnMurder) +e

lnbirth $=\mathrm{f}$ (lnInflation, lnPoverty, GDP per capita growth, lnmortality, lnillness, lnMurder) + e

lnbirth $=\mathrm{f}$ (lnInflation, lnPoverty, unemployment, GDP per capita growth, lnmortality, lnillness) +e

where e denotes the random error.

\section{FINDING}

The average births for the decade of the 1960s (1960 1969) represent the highest births in the history of Jamaica, and has been declining ever since (Figure 1). The rate of growth prior to the 1960s was an increasing one, which plateaus in the 1960s and has been declining at an increasing rate since the 1960 s.

Figure 2 illustrates the annual registered births in Jamaica from 1989 to 2009. Annual births in Jamaica are best fitted by a polynomial function $\left(r^{2}=0.8615\right)$.

Log annual registered births is fitted by a linear function $\left(\mathrm{r}^{2}=0.79\right)$-Figure 3 .

Table 1 presents information on the hypothesis 1 (Eq.1). Log murder accounts for $63.8 \%$ of the explained variance $(79.6 \%)$, with GDP per capita growth accounting for $15.9 \%$. The two factors are negatively correlated with lnbirth.

Of the four variables entered into the initial model, one emerged as statistically significant factor of lnbirth, lnpo-
verty-F $=4.647, \mathrm{P}<0.011, \mathrm{R}^{2}=0.537$ (Table 2). Based on the adjusted explanatory power, the model is not a parsimonious one as this excludes the annual exchange rate or murder.

Log murder and exchange rate has a strong statistical correlation $\left(\mathrm{r}_{\mathrm{s}}=0.962, \mathrm{P}<0.0001\right)$ and poverty and the

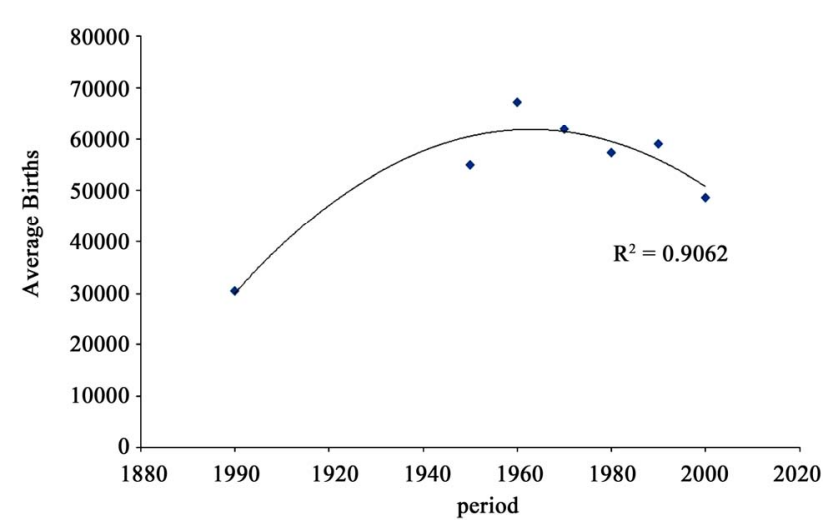

Figure 1. Average registered births for periods, 1900-1909 to 2000-2009; The periods are 1900-1909, 1950-1959, 1960-1969, 1970-1979, 1980-1980, 1990-1999 and 2000-2009.

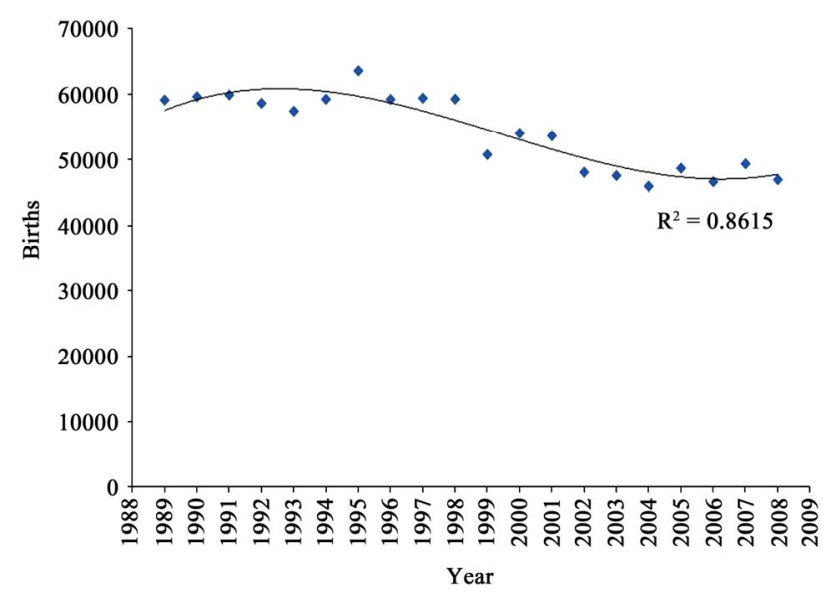

Figure 2. Annual registered births, 1989-2009.

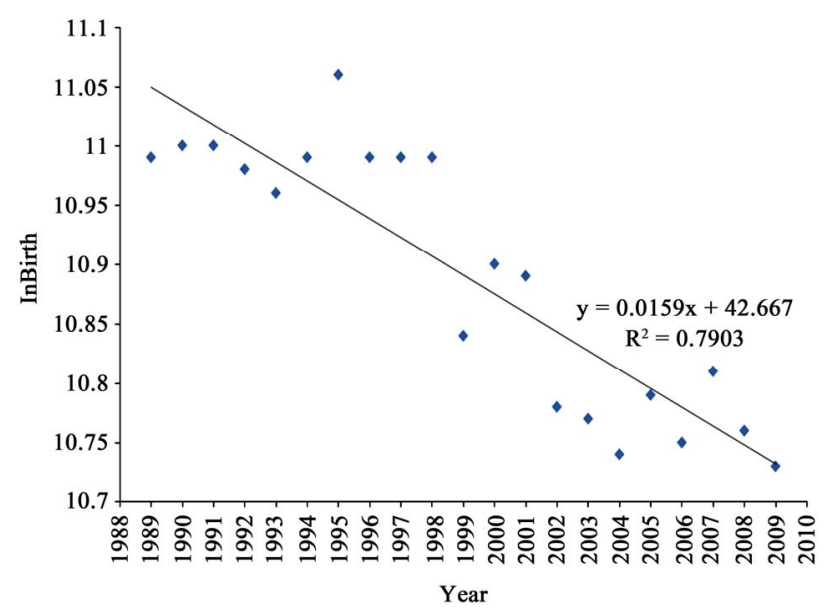

Figure 3. Log annual registered births from 1989-2009. 
Table 1. Ordinary least square regression of factors that influence lnbirth.

\begin{tabular}{|c|c|c|c|c|c|c|}
\hline Explanatory variable & $\begin{array}{l}\text { Unstandardized } \\
\text { Coefficients ‘b’ }\end{array}$ & Std. Error & Beta & Prob. & CI (95\%) & $\mathrm{R}^{2}$ change \\
\hline \multicolumn{7}{|c|}{ Model 1: } \\
\hline Constant & 12.371 & 0.298 & & 0.000 & $11.732-13.009$ & \\
\hline lnMurder & -0.218 & 0.044 & -0.798 & 0.000 & $-0.312--0.124$ & \\
\hline \multicolumn{7}{|c|}{ Model 2: } \\
\hline Constant & 12.590 & 0.242 & & 0.000 & $12.068-13.113$ & \\
\hline lnMurder & -0.246 & 0.035 & -0.901 & 0.000 & $-0.322--0.170$ & 0.638 \\
\hline lnGDP per capita growth & -2.776 & 0.873 & -0.411 & 0.007 & $-4.662--0.890$ & 0.159 \\
\hline \multicolumn{7}{|c|}{ Model 1: F statistic $[1,14]=24.630$, Prob. $<0.0001$} \\
\hline \multicolumn{7}{|c|}{ Model 1: $\mathrm{R}^{2}=0.638$, Adjusted $\mathrm{R}^{2}=0.612$} \\
\hline \multicolumn{7}{|c|}{ Model 2: F statistic $[2,13]=25.39$, Prob. $<0.0001$} \\
\hline Model 2: $\mathrm{R}^{2}=0.796$, Adju & $=0.765$ & & & & & \\
\hline
\end{tabular}

Dependent variable: lnAnnualRegisteredBirth (or lnbirth); Prob. denotes probability.

Table 2. Ordinary least square regression of factors that influence lnbirth.

\begin{tabular}{|c|c|c|c|c|c|}
\hline Characteristic & $\begin{array}{l}\text { Unstandardized } \\
\text { Coefficients "b" }\end{array}$ & Std. Error & Beta & Prob. & CI (95\%) \\
\hline Constant & 8.679 & 2.973 & & 0.010 & $2.377-14.980$ \\
\hline lnPoverty & 0.268 & 0.075 & 0.868 & 0.003 & $0.109-0.428$ \\
\hline lnUnemployment & -0.118 & 0.158 & -0.184 & 0.467 & $-0.453-0.217$ \\
\hline lnIllness & 0.006 & 0.119 & 0.011 & 0.961 & $-0.247-0.259$ \\
\hline lnMortality & 0.174 & 0.300 & 0.125 & 0.571 & $-0.463-0.810$ \\
\hline \multicolumn{6}{|c|}{ F statistic $[4,16]=4.647$, Prob. $<0.011$} \\
\hline \multicolumn{6}{|c|}{ Model $\mathrm{R}^{2}=0.537$, Adjusted $\mathrm{R}^{2}=0.422$} \\
\hline
\end{tabular}

Dependent variable: lnbirth; Prob. denotes probability.

exchange rate $\left(r_{s}=-0.818, P<0.0001\right)$. Hence, the researcher took out murder from the model in order to obtain the influence of the other variables, and poverty was excluded by the SPSS program because of a tolerance of 0.000 (Table 3). Of the four variables used in the initial model, only two emerged as statistical significant factors of lnbirth-exchange rate and lnunemployment- $\mathrm{F}=$ 16.431, $\mathrm{P}<0.0001$, and explain $80.5 \%$ of the variability in lnbirth (Table 3).

Table 4 shows information that test hypothesis 4 . Of the 5 variables, all of them emerged as statistically significant factors of lnbirth-F $=30.572, r^{2}=0.922$. Using beta weights, the exchange rate is the most influential factor affecting lnbirth (Table 4).

Of the five variables initially tested in hypothesis 5 , four emerged as statistically significant predictors of lnbirth—inflation, GDP per capita growth, mortality and mur- der, with an explanatory power of $90.6 \%-F=19.291, \mathrm{P}$ $<0.0001$ (Table 5).

Hypothesis 6 was tested and displayed in Table 6. Table 6 showed that of the 6 variables identified, four emerged as statistical significant factors of lnbirth-lnmortality, GDP per capita growth, lnmurder, and Ininflation, which account for $90.7 \%$ of the variability in lnbirth.

Two variables emerged as statistical significant factors of lnbirth, poverty and GDP per capita growth, with an explanatory power of $72 \%$ (Table 7). Based on the adjusted explanatory power, the model is not a parsimonious one excluding the annual exchange rate and/or murder.

Based on the seventh hypotheses, the final model that encapsulates the birth function can be expressed in Eq.5. The birth function (B) that relates to mortality (M), murder (R), GDP per capita growth (GDP), inflation (I) can be written as 
Table 3. Ordinary least square regression of factors influencing lnbirth.

\begin{tabular}{lccccc}
\hline Characteristic & Unstandardized Coefficients & Std. Error & Beta & Prob. & CI (95\%) \\
\cline { 2 - 3 } Constant & B & 1.888 & & 0.001 & $4.092-12.097$ \\
lnExchange Rate & -0.094 & 0.001 & -0.932 & 0.000 & $-0.007--0.003$ \\
lnInflation & 0.074 & 0.064 & 0.240 & 0.260 & $-0.061-0.209$ \\
lnUnemployment & -0.208 & 0.086 & -0.325 & 0.028 & $-0.391--0.026$ \\
InMortality & 0.340 & 0.195 & 0.244 & 0.100 & $-0.073-0.754$ \\
F statistic [4,16] $=16.431$, Prob. $<0.0001, \mathrm{R}^{2}=0.805$ & & & & \\
Adjusted $\mathrm{R}^{2}=0.755$ & & & &
\end{tabular}

Dependent variable: lnbirth; Prob. denotes probability.

Table 4. Ordinary least square regression of factors influencing lnbirth.

\begin{tabular}{|c|c|c|c|c|c|c|}
\hline \multirow{2}{*}{ Characteristic } & \multicolumn{2}{|c|}{ Unstandardized Coefficients } & \multirow{2}{*}{$\begin{array}{c}\text { Standardized } \\
\text { Coefficients } \\
\text { Beta }\end{array}$} & \multirow{2}{*}{ Prob. } & \multicolumn{2}{|c|}{ 95.0\% Confidence Interval for B } \\
\hline & $\mathrm{B}$ & Std. Error & & & Lower Bound & Upper Bound \\
\hline Constant & 7.585 & 1.367 & & 0.000 & 4.631 & 10.539 \\
\hline lnExchange rate & -0.005 & 0.001 & -0.912 & 0.000 & -0.006 & -0.004 \\
\hline lnInflation & 0.049 & 0.017 & 0.335 & 0.012 & 0.013 & 0.085 \\
\hline lnUnemployment & -0.145 & 0.062 & -0.252 & 0.035 & -0.279 & -0.012 \\
\hline lnGDP per capita growth & -2.209 & 0.502 & -0.376 & 0.001 & -3.293 & -1.124 \\
\hline lnMortality & 0.390 & 0.142 & 0.277 & 0.017 & 0.083 & 0.698 \\
\hline \multicolumn{7}{|l|}{$\mathrm{R}^{2}=0.922$} \\
\hline Adjusted $\mathrm{R}^{2}=0.891$ & & & & & & \\
\hline
\end{tabular}

Dependent variable: lnbirth; Prob. denotes probability.

Table 5. Ordinary least square regression of factors that influence lnbirth.

\begin{tabular}{|c|c|c|c|c|c|}
\hline Characteristic & $\begin{array}{l}\text { Unstandardized } \\
\text { Coefficients B }\end{array}$ & Std. Error & beta & Prob. & CI (95\%) \\
\hline Constant & 6.809 & 2.054 & & 0.008 & 2.232 - 11.386 \\
\hline lnInflation & 0.075 & 0.022 & 0.519 & 0.007 & $0.025-0.125$ \\
\hline lnUnemployment & -0.067 & 0.070 & -0.120 & 0.359 & $-0.222-0.088$ \\
\hline lnMortality & 0.579 & 0.213 & 0.378 & 0.022 & $0.104-1.054$ \\
\hline lnMurder & -0.220 & 0.035 & -0.808 & 0.000 & $-0.299--0.142$ \\
\hline \multicolumn{6}{|c|}{ F statistic $[5,10]=19.291$, Prob. $<0.0001$} \\
\hline \multicolumn{6}{|l|}{$\mathrm{R}^{2}=0.906$} \\
\hline
\end{tabular}

Dependent Variable: Inbirth; Prob. denotes probability. 
Table 6. Ordinary least square regression of factors that influence lnbirth.

\begin{tabular}{|c|c|c|c|c|c|}
\hline \multirow{2}{*}{ Characteristic } & \multirow{2}{*}{$\begin{array}{c}\text { Unstandardized Coefficients } \\
\text { B }\end{array}$} & \multirow{2}{*}{ Std. Error } & \multirow{2}{*}{ Beta } & \multirow{2}{*}{ P value } & \multirow{2}{*}{ CI (95\%) } \\
\hline & & & & & \\
\hline Constant & 6.541 & 2.666 & & 0.037 & $0.511-12.572$ \\
\hline lnMortality & 0.590 & 0.243 & 0.386 & 0.038 & $0.041-1.140$ \\
\hline lnGDP per capita growth & -2.704 & 0.843 & -0.400 & 0.011 & $-4.612--0.796$ \\
\hline lnMurder & -0.202 & 0.062 & -0.742 & 0.010 & $-0.344--0.061$ \\
\hline lnInflation & 0.074 & 0.025 & 0.511 & 0.017 & $0.017-0.131$ \\
\hline lnPoverty & 0.012 & 0.083 & 0.042 & 0.888 & $-0.176-0.201$ \\
\hline lnIllness & -0.063 & 0.074 & -0.111 & 0.416 & $-0.229-0.104$ \\
\hline \multicolumn{6}{|c|}{ F statistic $[6,9]=14.552, \mathrm{P}<0.0001$} \\
\hline \multicolumn{6}{|l|}{$\mathrm{R}^{2}=0.907$} \\
\hline Adjusted $\mathrm{R}^{2}=0.844$ & & & & & \\
\hline
\end{tabular}

Dependent variable: lnbirth.

Table 7. Ordinary least square regressions of explanatory factors of lnbirth.

\begin{tabular}{lccccc}
\hline \multirow{2}{*}{ Model } & Unstandardized Coefficients & Std. Error & beta & P value & CI (95\%) \\
\cline { 2 - 3 } Constant & B & 2.770 & & 0.058 & $-0.240-11.832$ \\
InPoverty & 5.796 & 0.080 & 0.728 & 0.019 & $0.042-0.389$ \\
lnUnemployment & 0.215 & 0.142 & -0.060 & 0.812 & $-0.343-0.275$ \\
lnMortality & -0.034 & 0.287 & 0.321 & 0.141 & $-0.173-1.078$ \\
lnInflation & 0.453 & 0.038 & 0.295 & 0.274 & $-0.039-0.125$ \\
lnGDP per capita growth & 0.043 & 1.139 & -0.453 & 0.037 & $-5.146--0.184$ \\
lnIllness & -2.665 & 0.138 & 0.065 & 0.801 & $-0.266-0.337$ \\
F statistic $[6,12]=5.148, \mathrm{P}<0.0001$ & 0.036 & & & & \\
$\mathrm{R}^{2}=0.720$ & & & & & \\
Adjusted $\mathrm{R}^{2}=0.580$ & & & & & \\
\hline
\end{tabular}

Dependent variable: lnbirth.

$$
\mathrm{B}=\alpha \mathrm{M}^{\beta} \mathrm{R}^{\gamma} \mathrm{GDP}^{\omega} \mathrm{I}^{v}
$$

However, taking the logarithms yields

$$
\ln (\mathrm{B})=\delta+\beta \ln (\mathrm{M})+\gamma \ln (\mathrm{R})+\omega \ln (\mathrm{GDP})+v \ln (\mathrm{I})+\mathrm{e}
$$

where $\delta=\ln (\alpha)$. This is a nonlinear function in the variables M, R, GDP and I, but the parameters are linear, $\delta, \beta$, $\gamma, \omega$, and $v$. These parameters are integers. With there being a strong statistical correlation between annual exchange rate and murder $\left(r_{s}=0.962\right)$ - Table 4. Hence, the function (Eq.7) was modified to included lnExchange rate by excluding lnmurder; the function was change and can be written as:

$$
\mathrm{B}=\alpha \mathrm{M}^{\beta} \mathrm{U}^{\gamma} \mathrm{GDP}^{\omega} \mathrm{I}^{\nu} \mathrm{E}^{\rho}
$$

However, taking the logarithms yields

$$
\begin{aligned}
\ln (\mathrm{B})= & \delta+\beta \ln (\mathrm{M})+\gamma \ln (\mathrm{U}) \\
& +\omega \ln (\mathrm{GDP})+v \ln (\mathrm{I})+\rho \ln (\mathrm{E})+\mathrm{e}
\end{aligned}
$$

with the exclusion of annual exchange rate (exchange, E), unemployment emerged as a factor (U). A positive parameter is an upward sloping curve and a negative parameter is a downward sloping curve (Table 5).

\section{DISCUSSION}

The current work shows that there is a positive correlation between births and 1) inflation, 2) GDP per capita growth, and 3) mortality, while there were negative associations between births and 1) unemployment, 2) murder and 3) annual exchange rate. The correlation between poverty and birth is positive $\left(\mathrm{r}_{\mathrm{s}}=0.715, \mathrm{P}<0.0001\right)$, which disappears when annual exchange rate or murder is include in a single model with other various such as poverty. The macroeconomic factors of birth are a non-linear function, with linear parameters and influence of annual exchange rate or murder. Murder or the annual exchange rate is the most influential factor explaining birth 
in Jamaica. Murder is a cause of birth in Jamaica as well as the annual exchange rate, and these factors are having a negative influence on annual births.

The study of murder is more seen as a cause crime than a predictor of health. This perspective is a rationale for plethora of studies in criminology, law, sociology, anthropology, criminal justice, forensic, public policy, political science, and history. The general focus of murder is embedded in the perspective of the concept and accounts for the neglect of the phenomenon in health research and epidemiology. Like MacDonald argued, violence is a public health concern which is a justification for inquiries on murder as a cause of mortality, and by extension epidemiology and health research. "Epidemiology may be defined as the study of the distribution and determinants of disease in a human population” argued Barker and Hall [36], which although is a simplistic conceptualization of the discipline of epidemiology, highlights the correlation between ill-health and it causes such as plague, cholera, hypertension, arthritis, heart diseases, diabetes mellitus and diseases causing pathogens. Within the context of epidemic diseases in Jamaica, murder cannot be excluded as it is among the 10 leading causes of mortality and it is even greater than HIV [6].

While murder is cause of mortality in Jamaica, it is among the determinants of births. In classifying the determinants of fertility, Kiser and Whelpton [14], Bongaarts [15], and other research scholars identified many factors; but did not examine the role of murder on births. The present work found that compressor of birth (or fertility), and it has the most influence on births. The explanation of murders being negatively correlated with birth is not surprising as victims of murder are mostly young people of child bearing ages. Statistics on crimes in Jamaica, particularly murder, revealed that on average $83 \%$ of victims are ages 15 - 49 years old [31]. Murder which is primarily committed by people within the reproductive ages, against those in reproductive ages account for a significant decline in the fertility, as those killed are not likely to have children after death.

With a strong direct correlation between murder and annual exchange rate in Jamaica, the influence of murder is equivalent to that of changes in the annual exchange rate. "More than half of the goods regularly purchased by consumers [being] sensitive to changes in the exchange rate" according to Harriott [37], which links changes to the exchange rate and the economic climate. An upward movement in the exchange rate denotes that the prices of imported goods would be more expensive, people will be force to purchase less with the same amount of money and this will affect choices in other non-imported goods. This paper showed a negative correlation between the annual exchange rate and birth (or fertility) which implies that imported economic hardship is a natural contraceptive measure.
An inverse correlation exists between GDP per capita growth and births, indicating that in periods of economic growth, births falls and in times of recession, births increases. Such an issue appears conflicting with previous argued perspective, but it is paradoxically in nature and offers an insight into money (or the lack of) and fertility. With the direct association between inflation and births, this means that domestic economic hardship in an economy is related to women giving up their reproductive rights to men in order to survive. Inflation is re-inforcing the negative correlation of GDP and births, and economic hardship is therefore a birth stimulant and not a contraceptive measure. It follows that during economic hardship, the vetoing rights over reproductive matters are held by men who use financial resources as a tool to dictate the non-usage of contraception. Women in wanting to survive, because of the economic hardship, forego using contraception and non-contraception is also used to lure financial stable men, which justifies increased births during economic decline. Therefore the human rights that women should have over their bodies, sexual autonomy [38], disappear in periods of economic downturn.

The economic downturn in the Jamaican economy can be measured using self-reported information. In 2007, a study conducted by Powell et al. [18] found that 1) 31 out of every 50 Jamaicans indicated that their salaries (or wages) were unable to cover expenses, 2) 36 out of every 50 respondents indicated that they were concerned about the likelihood of being unemployed in the next 12 months, and 3) 30 out of every 50 people mentioned that currently their lives were worse off or at most the same compared to 1 year ago. Remittance which is source of money and an indicator of people's economic situation has declined since the economic recession in the United States since 2007. A study conducted by Ramacon [39] found that 52\% of those who received remittances in 2010 indicated that they were receiving less money since the global recession. Within the context of the current findings, births are expected to rise in Jamaica post 2007, which is supported by the births statistics for 2008. Births in 2008 increased by $1.1 \%$ compared to 2007 as nation experience an economic downturn brought upon by the global induced recession. With Berer's argument that "Nor is sex work itself widely understood to arise from the social and economic marginalization of poor, unemployed, migrant, refugee and displaced women” [38], then the decline GDP growth increases the likelihood of unprotected sex and accounts for more births in the society. In 2007, the mean annual food prices increased by 109\% over 2002 [28], suggesting that marginalized groups, including poor, uneducated, and unemployed women, will exchange their sexual autonomy for survivalability and including in this transfer is the low (or non) usage of contraception. The resultant effects of such situations account for the increased 
fertility that emerged in this work, making poverty a birth stimulant.

Another factor of importance is mortality. The direct correlation between mortality and birth (or fertility) appears paradoxical in nature; but this is not. Computing from the Statistical Institute of Jamaica's demographic public [6] revealed that over one-half of deaths were among seniors. Disaggregating the Jamaican mortality statistics showed that $59.8 \%$ were people ages $50+$ years (with $93 \%$ being $60+$ years) and $31.9 \%$ were of the reproductive ages (15 49 years old). It can be extrapolated from the current work and the aforementioned statistics that increased mortality is set against more births, which mitigates against lowered population.

All the variables identified by this research based on Davis and Blake's proposition [40], would be considered as intermediate variables that indirect affect fertility. Then Bongaarts [15], quantify the perspective of Davis and Blake [40]. The socio-economic and cultural variables, indirect determinants of fertility $[15,40,41]$, come across as secondary factors. However, this paper shows that the explanatory power of these 'intermediate variables' (such as murder, mortality, inflation, unemployment, exchange rate, GDP per capita) are more influential factors than previously identified, and must be included within the ambits of fertility dialogue as direct determinants, particularly murder and exchange rate. The influence of murder on birth (or exchange rate) is birth cannot be denied as well as its strength, especially if most of the victims are within the reproductive ages of 15 - 49 years as is the case in the Caribbean. Hence, the murder pattern in the Caribbean, particularly Jamaica, must with urgency be included into demography, health statistics and epidemiology as murder is a public health epidemic that directly influences birth.

\section{CONCLUSIONS}

Outside of abortion, menopause, still birth, contraception, age of first marriage, frequency of sexual intercourse, duration of fertile period, lactational infecundability, age of first menarche, age of first sexual intercourse, attitude toward the family, financial resources, education of mother, and crowding, there are factors still not currently recorded in the literature. Among the factors not noted in the literature are inflation, unemployment, mortality, exchange rate or murder, and GDP per capita growth are determinants of birth (or fertility). These findings add to the literature on factors that influence birth and the determinants are non-linear, while their parameters are linear integers. The work provides pertinent insights into the phenomenon of birth and their determinants and can be used to guide the public health discourse, public policy and its broad appeal to policy makers as well as epidemiological inquiry.
In summary, murder is more that a crime it is a cause of birth decline, suggesting that public health practitioners as well as epidemiologists must take this factor into account as it is a birth determinant.

\section{REFERENCES}

[1] Newell, C. (1988) Methods and models in demography. The Guilford Press, New York.

[2] Preston, S.H., Heuveline. P. and Guillot. M. (2001) Demography: Measuring and modelling population processes. Blackwell Publishers, Massachusetts.

[3] Rowland, D.T. (2003) Demographic methods and concepts. Oxford University Press, Oxford.

[4] Cox, P.R. (1976) Demography. 5th Edition, Cambridge University Press, New York.

[5] Bourne, P.A. (2011) Health demography II. Socio-Medical Research Institute, Kingston.

[6] Statistical Institute of Jamaica (STATIN) (1981-2011) Demographic statistics, 1980-2010. STATIN, Kingston.

[7] STATIN (1961-1990) Statistical yearbook, 1960-1989. STATIN, Kingston.

[8] Jamaica, Family Planning Board (1994, 1998, 2005, 2010) Reproductive health survey, 1993, 1997, 2002, 2008. Family Planning Board, Kingston.

[9] Orleans, L.A. (1975) China's experience on population control: The elusive model. World Development, 3, 497-525. doi:10.1016/0305-750X(75)90051-0

[10] Potts, M. (2006) China’s one child policy: The policy that changed the world. $B M J, 333,361-362$. doi:10.1136/bmj.38938.412593.80

[11] Zulu, E. (2010) Family planning, fertility and poverty in Africa: Overview of issues. Seminar on Fertility and Poverty: Micro and Macro Linkages, Southampton, 28-29 January 2010.

[12] Cincotta, R.P. and Haddock, S. (2006) Family planning in Sub-Saharan Africa: Reducing risks in the era of AIDS. Population Action International, 1, 1-5.

[13] Bulatao, R.A. (1984) Reducing fertility in developing countries: A review of determinants and policy levers. World Bank Staff Working Papers No. 680 and Population and Development Series No. 5.

[14] Kiser, C.V. and Whelpton, P.K. (1953) Social and psychological factors affecting fertility. Population Studies, 7, 95.

[15] Bongaarts, J. (1978) A framework for analysing the proximate determinants of fertility. Population and Development Review, 4, 105-132. doi:10.2307/1972149

[16] Younglai, E.V., Holloway, A.C. and Foster, W.G. (2005) Environmental and occupational factors affecting fertility and IVF success. Human Reproduction, 11, 43-57.

[17] Adhikari, R. (2010) Demographic, socio-economic, and cultural factors affecting fertility differentials in Nepal. BMC Pregnancy and Childbirth, 10, 19. doi:10.1186/1471-2393-10-19 
[18] Powell, L.A., Bourne, P. and Waller, G. (2007) Probing Jamaica's political culture, volume 1: Main trends in the July-August 2006 leadership and governance survey. Centre for Leadership and Governance, Kingston.

[19] Harriott, A. (2004) Introduction. In: Harriott, A., Brathwaite, F. and Wortley, S., Eds., Crime and Criminal Justice in the Caribbean, Arawak Publishers, Kingston, 1-7.

[20] Boxill, I., Lewis, B., Russell, R., Bailey, A., Waller, L., James, C., Martin, P., Gibbs, L. and Seligson, M.A. (2007) Political culture of democracy in Jamaica: 2006. Americas barometer. The University of the West Indies, Kingston.

[21] Simmonds, L.E. (2004) The problem of crime in an urban slave society: Kingston in the early nineteenth century. In: Harriott, A., Brathwaite, F. and Wortley, S., Eds., Crime and Criminal Justice in the Caribbean, Arawak Publishers, Kingston, 8-34.

[22] Mars, J.R. (2004) Police abuse of force in Guyana: Applying lessons from the United States. In: Harriott A., Brathwaite F. and Wortley S., Eds., Crime and Criminal Justice in the Caribbean, Arawak Publishers, Kingston, 206-224.

[23] Robotham, D. (2003) Crime and public policy in Jamaica. In: Harriott A., Ed., Understanding Crime in Jamaica: New Challenges for Public Policy, University of the West Indies Press, Kingston, 197-238.

[24] Headley, B. (1994) The Jamaican crime scene: A perspective. Eureka Press, Mandeville.

[25] Sives, A. (2003) The historical roots of violence in Jamaica: The Hearne report 1949. In: Harriott, A., Ed., Understanding Crime in Jamaica: New Challenges for Public Policy, University of the West Indies Press, Kingston, 49-62.

[26] MacDonald, G. (2002) Violence and health: The ultimate public health challenge. Health Promotion International 17, 293-295. doi:10.1093/heapro/17.4.293

[27] Grabill, W.H., Kiser, C.V. and Whelpton, P.K. (1958) The fertility of American women. Wiley, New York.

[28] Planning Institute of Jamaica (PIOJ), Statistical Institute of Jamaica (STATIN) (1989-2011) Jamaica survey of living conditions, 1989-2010. PIOJ, STATIN, Kingston.
[29] PIOJ (1989-2010) Economic and social survey of Jamaica, 1988-2009. PIOJ, Kingston.

[30] Bank of Jamaica (BoJ) (1981-2010) Statistical digest, 1980-2009. Bank of Jamaica.

[31] Statistical Department, Jamaica Constabulary Force (19892009) Murder, 1989-2009. Jamaica Constabulary Force, Kingston.

[32] World Bank (2002) Jamaica survey of living conditions 1988-2000. World Bank, Washington DC.

[33] McCaw-Binns, A., Fox, K., Foster-Williams, K., et al. (1996) Registration of births, stillbirths and infant deaths in Jamaica. International Journal of Epidemiology, 25, 807-813. doi:10.1093/ije/25.4.807

[34] Fox, K. et al. (2006) Assessing the level of births and birth registration in Jamaica. Ministry of Health, Kingston.

[35] Mathers, C.D., Fat, D.M., Inoue, M., et al. (2005) Counting the dead and what they died from: An assessment of the global status of cause of death data. Bulletin of the World Health Organization, 83, 172-173.

[36] Barker, D.J.P. and Hall, A.J.( 1991) Practical epidemiology. 4th Edition, Churchill Livingstone, London.

[37] Harriott, K. (2000) Essential facts about inflation. Bank of Jamaica, Kingston. http://www.boj.org.jm/uploads/pdf/papers_pamphlets/pap ers_pamphlets_Essential_Facts_About_Inflation_.pdf

[38] Berer, M. (2004) Sexuality, rights and social justice. Reproductive Health Matters, 12, 6-11. doi:10.1016/S0968-8080(04)23130-5

[39] Ramacon, E.G. (2011) Remittances survey 2010. Bank of Jamaica (BOJ), Kingston. http://boj.org.jm/uploads/pdf/remittance survey results 2010.pdf

[40] Davis, K. and Blake, J. (1956) Social structure and fertility: An analytic framework. Economic and Cultural Change, 4, 211-235. doi:10.1086/449714

[41] Alene, G.D. and Worku, A. (2009) Estimation of the total fertility rates and proximate determinants of fertility in North and South Gondar zones, Northwest Ethiopia: An application of the Bongaarts' model. Ethiopian Journal of Health Development, 23, 19-27. 